\title{
EVALUATION OF BONE HEIGHT CHANGES IN SPLINTED AND NON-SPLINTED TWO IMPLANT RETAINED MANDIBULAR OVERDENTURES WITH LOCATOR ATTACHMENT (RCT)
}

\author{
Nora M. Sheta* and Mohamed Abdel Hakim Abdel Aal **
}

\begin{abstract}
Purpose: The Target of this study was radiographic evaluation of the bone height changes in splinted and non-splinted two implant retained mandibular overdentures with Locator attachment

Materials and Methods: In this study, a total of twenty eight implants with locator attachment were placed in fourteen patients with completely edentulous mandible. The patients were randomly grouped into two groups: Splinted implants Group: Patients had received overdenture reinforced with metallic framework \& the locators' metallic housings were embedded to the metal framework. Unsplinted implants Group: Patients had received implant overdentures retained with two unsplinted or solitary locator attachments. Bone height change measurements around each implant were performed at day of loading, six then twelve month using CBCT scan.
\end{abstract}

Results: The results of this study revealed that the least bone height changes was noticed in splinted implants Group. Compared to Unsplinted implants Group with no statistically significant difference throughout the whole study period.

Conclusions: Within the limitations of this short-term randomized controlled study, it may be concluded that there are no difference between splinting implant with metal framework enforcing the overdenture and connected to the metal housing of locator attachment in the amount of bone height changes around the implant than the unsplinted implant.

KEYWORDS: edentulous mandible, overdenture, metal reinforcement, splinted, unsplinted, implant locator attachment.

\section{INTRODUCTION}

Mandibular overdenture assisted with two interforaminal implants became the usual care routine for treating completely edentulous patients ${ }^{(1)}$. Attachments are used with implants to improve retention and stability of the mandibular overdenture ${ }^{(2)}$, selection of the attachment and its degree of resiliency depend on several factors from which are implant length, distribution, distance between anterior and posterior implants, arch shape and the interarch space available. ${ }^{(2-5)}$

* Assistant Professor, Department of Prosthodontics, Faculty of Dental Medicine, Cairo University.

** Lecturer of Removable Prosthodontics. Faculty of Oral and Dental Medicine, Beni-Suef University 
Straight connection between implants in v shaped arches can affect tongue space which may indicate the use of stud attachments instead of bars. ${ }^{(6,7)}$ Locator stud attachments have many advantages as it can be used with inter-implant angulation reaching $40^{\circ}$, it also allows for dual retention; mechanical which is provided by engaging the shallow undercut area on the abutment by the outer margin of the attachment and frictional retention provided by the nylon male and its female component, moreover locators can be used to correct implant angulation by using it without the inner retention feature. ${ }^{(8-10)}$ The reduced height of this attachment is advantageous for cases with limited interocclusal space or when retrofitting an existing old denture. ${ }^{(11)}$

The implant overdentures anchorage design was classified into two groups: implants splinted to the bar or superstructure, or isolated and not splinted. ${ }^{(12)}$ splinted attachments using bars needs more room within the denture than unsplinted attachments using locator, ball anchors or magnets and it is also difficult to add an anchorage attachment to the bars. On the other side the use of unsplinted attachments for implant overdenture suites a wide variety of patients due to the smaller space required within the prosthesis as well as its simple fabrication process compared to bar attachment which needs a skillful laboratory technician. ${ }^{(5,8,13.14)}$

The aim of this study is to evaluate the bone height change of splinted and unsplinted mandibular overdenture with locator attachment

\section{PATIENTS AND METHODS}

Fourteen completely edentulous male patients seeking for implant placement were enrolled from the out-patient clinic of clinical Removable Prosthodontics Department, Cairo University. All patients were selected according to certain intrusion and extrusion criteria for implant installation.

Conventional maxillary \& mandibular complete dentures were fabricated before implant placement.
The mandibular denture was then duplicated to be used as a radiographic stent. CBCT scanning was made before implant installation to evaluate the bone quality \& quantity.

The radiographic stent was then converted into a conventional surgical stent, by drilling holes at the prospected implant areas installation to allow accurate implant placement.

All patients had received two implants installed in the mandibular inter-foraminal areas in the canine areas. All installed implants were BIOMET3i implant of diameter $4 \mathrm{~mm} \& 13 \mathrm{~mm}$ in length. The implants were installed following the manufacturer instructions, starting with the pilot drill, intermediate, and final drill.

All patients had undergone the two stage surgical protocol. The complete dentures were modified and relined with a soft liner (silicone based, PROMEDICA) at the day of surgery. Patients were recalled after 3 month for a Secondary stage surgery (uncover the buried implant) and then locator attachments were installed (Certain locator abutment BIOMET 3i)

Patients' Grouping: Patients were then randomly divided into two equal groups; Splinted implants Group: Patients had received overdenture reinforced with metallic framework \& the locators' metallic housings were embedded with the metal framework. Unsplinted implants Group: Patients had received implant overdentures retained with two un-splinted or solitary locator attachments

\section{Splinted group:}

One layer was removed from the fitting surface of the existing lower denture and two grooves were made in the denture opposite to the attachments till complete seating of the denture occurred.

Locator metal housing and the processing cap were placed on top of the attachment in the patient's mouth. A relining impression was made using a 
medium addition silicone rubber base impression material (Speedex, Coltène/Whaledent Company) with the patient mouth closed in centric occluding relation position.

An attachment analogue placed into the picked up processing cap after impression removed from the patient mouth, and then a production of a plaster tooth index was carried- out.

The relined denture with the attachment analogue were poured into a stone cast, with the plaster tooth index placed in the relining unit REFLEX $^{\mathrm{TM}}$ RELINE JIG (C) 2013 Lang Dental Mfg. Co). A rubber base index was made on the occlusal surface of the denture as a guide for controlling the space between the denture and the cap. Alayer of base plate wax with two tissue stops posteriorly as a relief wax was placed on the cast which was then duplicated into an investment model. A retentive mesh will be waxed on the investment model (Fig1A)

The retentive meshwork will then be sprued and casted (cobalt chromium alloy). (Fig1 B) After casting of the metal framework, the relieved denture was adapted over the metal framework to check for proper adaptation

The fitting surface of the metal framework was layered with a pink opaquer and then adapted onto the model. A soft mix of self-cure acrylic resin was

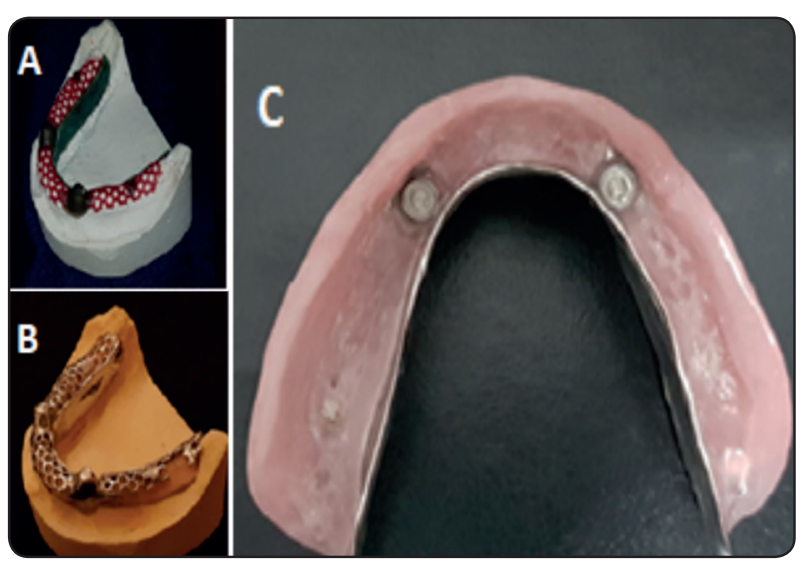

Fig. (1 A, B, C) laboratory steps for construction of metal framework, Embedment of metal housing on it placed over the metal framework, and then the denture was adapted over it, and the whole assembly was placed back in the relining unit.

The denture was trial placed in the patient's mouth to verify the fit and occlusion, as well as to ensure that there was no interference between the metal housing and the metal framework of the denture. The metal framework facing the housing was roughened and subjected to airborne particle abrasion using 50$\mu \mathrm{m}$ aluminous oxide, while the metal housing were cleaned and dried. A metal-bonding acrylic agent (U bar metal bonding cold cure [Protech]) was applied then picked- up directly inside the patient's mouth by utilizing a chemically polymerizing resin material (CHAIRSIDE Attachment Processing Material [Zest Dental Solutions]) as per the manufacture recommendations The prostheses were adjusted, finished, and polished as needed. The black processing inserts were removed and replaced with nylon cap. ${ }^{(16)}$ (Fig1C)

\section{Un-splinted group:}

Pick-up procedures: The areas opposite the locators were marked on the fitting surface of the mandibular complete denture. The fitting surface of the denture directly above the implants was hollowed. Relief was made to these areas and enough space was made to accommodate the locators.

A small hole was made at the lingual flange to allow for escape of excess cold curing polymerizing resin during direct picking- up. A sterile rubber dam sheet was adapted on each locator's abutment during the pickup procedure then white block out spacers were slipped around the locator abutments to facilitate the pick-up procedure (Fig 2 A,B)

The metal housing which is already installed with a black processing cap was placed directly over the locator abutments. Cold curing resin was placed in the relieved areas of the denture and the denture was seated in the patient's mouth. (Fig 2 C) 
The resin was left to polymerize while the patient was closing in centric occluding relation with minimal pressure. Denture was removed, trimmed and polished with the metal housings picked up in its fitting surface. (Fig 2 D) then the black processing cap was removed and the pink Locator replacement male retention cap was placed.

Oral hygiene demonstrations was provided with the cleaning aids necessary to maintain hygiene of the prostheses and the oral cavity.

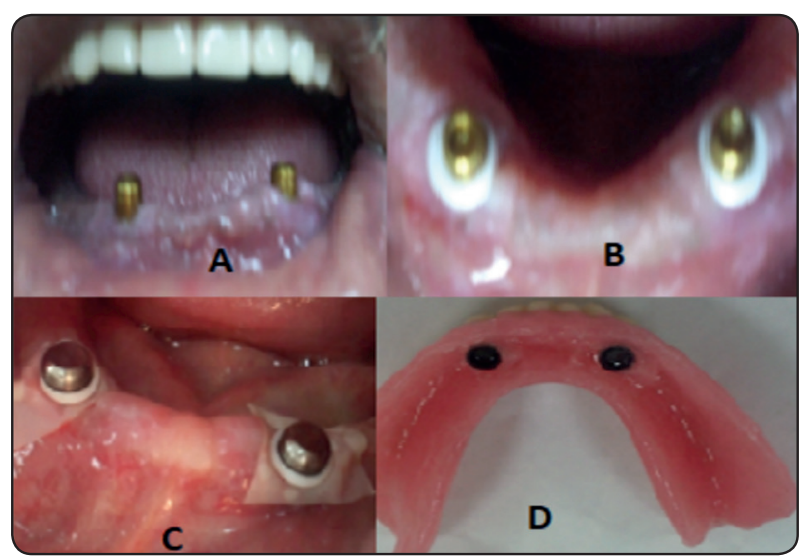

Fig. (2 A, B, C, D) direct pick up procedure

\section{Radiographic Evaluation :}

Crestal bone height changes were evaluated with the aid of Cone beam computed tomography (CBCT) at three months, six \& twelve months after implants' loading (Dentures' insertion).

Bone height was measured, as a distance between implant apex and the highest point of bone-implant in contact using software (Mimics, Materialise HQ, Technologielaan 15) the mean values of the midmesial, mid-distal, mid-buccal and mid-lingual were calculated, tabulated and statistically analyzed. (Fig 3)

\section{Statistical analyses and Methods}

Fourteen patients attempted to the course of follow- up period (1 year). The results of this study were statistically analysed to evaluate the bone height changes that occurred in around the implants

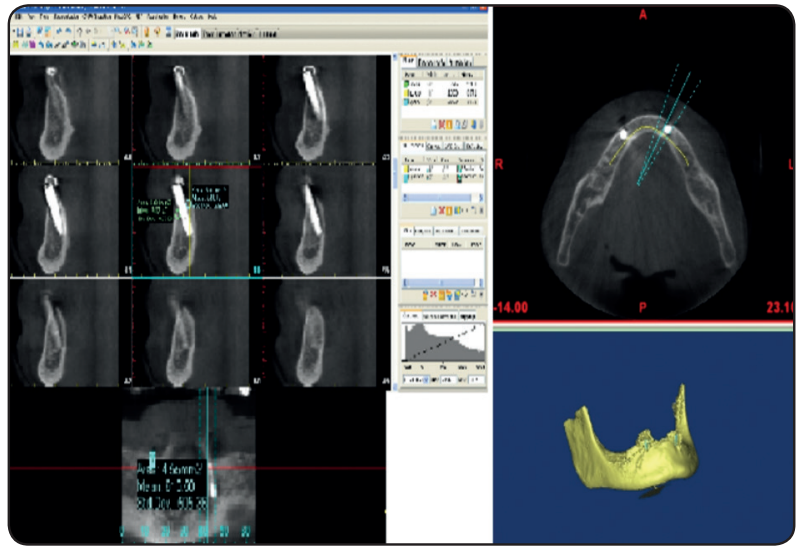

Fig. (3) Bone height measurements using mimics soft ware

placed in the mandibular canine region between overdenture reinforced with metallic framework with the locators' metallic housings cemented to the metal framework. (Splinted implants Group) and overdentures retained with two un-splinted or solitary locator attachments (Un splinted implants Group)

The Mean values and the standard deviation (SD) were calculated for each variable at day of prosthesis loading, six month and twelve month later.

The normal distribution of parameters were tested by Shapiro-Wik test. Normally distributed continuous variable were tested using unpaired-T student test or ANOVA. Paired t-test or ANOVA with repeated measures were used to study the change by time in each group.

Probability values $\leq 0.05$.all calculations were made with the DPSS software package (version 13.1: SPSS Inc)

\section{RESULT}

As confirmed in table 1 throughout the whole follow up period there was no statistically significant difference between the splinted and unsplinted groups with the least mean difference within splinted group. 
TABLE (1) The mean bone height, standard deviation and a result unpaired-T student test for the change by time around the implants within each group

\begin{tabular}{|c|c|c|c|}
\hline Time & $\begin{array}{c}\text { Splinted } \\
\text { Group } \\
\text { Mean } \mathbf{\pm} \text { SD }\end{array}$ & $\begin{array}{c}\text { unSplinted } \\
\text { Group } \\
\text { mean } \mathbf{\pm} \text { SD }\end{array}$ & P -value \\
\hline Day of loading & $12.5300 \pm .024$ & $12.5300 \pm \mathbf{0} .24$ & 0.99 \\
\hline Six months & $12.1921 \pm \mathbf{0} .29$ & $12.0950 \pm \mathbf{0 . 3 6}$ & 0.44 \\
\hline Twelve months & $11.8428 \pm \mathbf{0} .27$ & $11.7457 \pm \mathbf{0} .35$ & 0.42 \\
\hline
\end{tabular}

The mean difference of bone height changes by time within each group revealed that there is no statistically significance difference from time of loading to six month and from six months to one year with the least mean difference of bone height loss was from six to one year. For the splinted group the mean difference is 0.3379 from three to six month while from six to twelve month the mean difference is 0.3493 with $\mathrm{p}$ value $=0.901$. For the unsplinted group the mean difference is 0.4350 from three to six month while from six to twelve month the mean difference is 0.3493 with $p$ value $=0.355$

TABLE (2) The mean difference \& standard deviation values for the change by time in bone height around implant between the two groups

\begin{tabular}{|c|c|c|c|}
\hline Interval & $\begin{array}{c}\text { Splinted } \\
\text { Group Mean } \\
\text { difference } \pm \text { SD }\end{array}$ & $\begin{array}{c}\text { unSplinted } \\
\text { Group Mean } \\
\text { difference } \pm \text { SD }\end{array}$ & P -value \\
\hline $\begin{array}{c}\text { Day of loading } \\
- \text { six months }\end{array}$ & $-0.338 \pm 0.2428$ & $-0.435 \pm 0.3188$ & 0.37 \\
\hline $\begin{array}{c}\text { six months- } \\
\text { twelve months }\end{array}$ & $-0.349 \pm 0.16415$ & $-0.349 \pm 0.08713$ & 0.99 \\
\hline $\begin{array}{c}\text { Day of loading- } \\
\text { twelve months }\end{array}$ & $-0.687 \pm 0.24001$ & $-0.784 \pm 0.32661$ & 0.37 \\
\hline
\end{tabular}

As confirmed in table 2, comparing between the mean differences of bone height changes between the two groups there are no statistically significance difference from time of loading to six month and from six months to twelve months with p value 0.37 and 0.99 respectively.

\section{DISCUSSION}

Two implant retained overdenture is considered a useful treatment option to restore the mandibular completely edentulous ridge; it is cost effective and can be used in severely ridge resorption to enhance the overdenture retention and support. ${ }^{(1,15)}$

Splinting of implants together may allow for favorable stress distribution and may induce less crestal bone resorption than the un-splinted implants. ${ }^{(16,17)}$

Bar attachment is the attachment of choice to splint implants, help in stress distribution, transfer stresses to more apical direction and it also help in retention and stability of the prosthesis The bar construction needs more vertical space to accommodate the attachment, whereas individual implants require lesser space. . $^{(13,14,18,19)}$

Technique and laboratory procedures for studs attachment are simpler than that of the bar attachment. If the implant is deeply inserted into the alveolar bone, then locator abutment with variable heights are preferred over other abutments. The use of locator attachment can adjust retention because there are different inserts in the matrix. It can be used in small inter-arch space also need less hygienic maintenance in spite that the most common complication of implant bar retained overdenture is fracture of denture base due to insufficient thickness of the denture base.$^{(10,11,18,19)}$

In this study; metal reinforcement of the overdenture is used and attached to the locators metal housings to enhance the rigidity of the denture base and to decrease the ability of it fracture as well as the framework is attached to the metal housing to attain favorable stress distribution of force 
perimplant and decrease marginal bone $\operatorname{loss}^{(20,21)}$. Several studies revealed that the type of framework material affect the amount of stress concentration around the implant. . $22,23,24)^{2}$

Throughout the whole follow-up period of this study there was statistically non-significant difference between the splinted and un-splinted groups with the least mean difference within splinted group. Cobalt-Chromium alloy was utilized in framework fabrication in the splinted group as many studies clarified that the pattern of stress distribution among abutments depends on the alloy type used for framework fabrication ${ }^{(23,24,25)}$ The load application in a framework for implant prosthesis produces deformation energy in the system that causes flexion. ${ }^{(26)}$

If a great amount of deformation energy is consumed by the framework on a given point, reduction of the transmitted energy happens, decreasing the stress concentration in other sites. Accordingly, the elastic modulus of the alloy influences the type of deformation and consequently the tension transmitted to the abutments. ${ }^{(26)}$ Rigidity of the framework and perfect fit to all abutments have been considered as basic requirements for correct force distribution

The increased crestal bone loss in the unsplinted group, may be due to the fact that acrylic resin has a low modulus of elasticity and so would flex more, resulting in more deformation and more transmission of stresses to the underlying implants. So more stresses to the implant will result in more loading of the implants and, consequently changes in bone height. ${ }^{23,24)}$

The bone height changes throughout the whole study period in both groups was expected, as slight marginal bone loss after implant placement has been reported as a common phenomenon. It is thought to be the result of several contributing factors as bone remodeling during healing, inadvertent stress distribution to the marginal bone tightening of the implant during placement or excessive loading force. ${ }^{(27)}$
There was no statistically significance difference from time of loading to three month later and for six months later. Marginal bone height loss had continued till the end of the study period which is most probably due to bone remodeling that occurs after the first few months and also due to the stresses resulting from loading of the implants as the implant interface allows to adapt to its biomechanical situation thus explaining the reason why the bone height reduction decreased in the study period of six to twelve month. ${ }^{(27,28)}$

Several studies clarified that the attachment system does not seem to influence marginal bone loss, the incidence of complications or implant survival in mandibular overdentures. There are no statistically significant difference in implant failures between the various attachment approaches. ${ }^{(29,30)}$ As a systematic review in 2019 concluded that: both splinted and un splinted attachment systems performed similarly, with no statistically significant differences present in marginal bone loss, complications and implant survival. ${ }^{(30)}$

\section{CONCLUSIONS}

Within the limitations of this short-term randomized controlled study, it may be concluded that there is no difference of splinting implant with metal framework enforcing the overdenture and connected to the metal housing of locator attachment in amount bone height changes around the implant than the solitarily un-splinted implant

\section{REFERENCES}

1- Shor A, Goto Y, Shor K. Mandibular two-implant-retained overdenture: prosthetic design and fabrication protocol. Compend Contin Educ Dent 2007; 28:80-88

2- Trakas T, Michalakis K, Kang K, Hirayama H. Attachment systems for implant retained overdentures: a literature review. Implant Dent 2006; 15:24-34.

3- Shafie HR. Clinical and Laboratory Manual of Implant Overdenture. Lowa, USA: Blackwell Publishing Company; 2007. 
4- Alsiyabi AS, Felton DA, Cooper LF. The role of abutmentattachment selection in resolving inadequate interarch distance: A clinical report. J Prosthodont 2005; 14:184-9.

5- Sadowsky SJ, Caputo AA. Effect of anchorage systems and extension base contact on load transfer with mandibular implant-retained overdentures. J Prosthet Dent 2000;84:327-34.

6- Walton JN, MacEntee MI, Glick N. One-year prosthetic outcomes with implant overdentures: A randomized clinical trial. Int J Oral Maxillofac Implants 2002;17:391-8.

7- Heckmann SM, Winter W, Meyer M, Weber HP, Wichmann MG. Overdenture attachment selection and the loading of implant and denture-bearing area. Part 2: A methodical study using five types of attachment. Clin Oral Implants Res 2001;12:640-7.

8- Kaneko T, Nakamura S, Hino S, Horie N, Shimoyama T. Two-implant-retained overdentures using locator attachments in completely edentulous patients with severely resorted mandible: a report of two cases. J Dent App 2016; 3:315-318.

9- Eltaftazani I, El-Anwar MA. Locator attachment versus ball attachment: 3-dimensional finite element study. 88th ed. Barcelona, Spain; 2010.

10- Evtimovska E, Masri R, Driscoll CF, Romberg E. The change in retentive values of locator attachments and hader clips over time. J Prosthodont 2009; 18:479-483.

11- Pasciuta M, Grossmann Y, Finger IM. A prosthetic solution to restoring the edentulous mandible with limited interarch space using an implant-tissue-supported overdenture: A clinical report. J Prosthet Dent 2005;93:116-20.

12- Misch CE. Dental Implant Prosthetics. 2nd ed. Mosby; 2014.

13- Payne AG, Solomons YF. Mandibular implant-supported overdentures: A prospective evaluation of the burden of prosthodontic maintenance with 3 different attachment systems. Int J Prosthodont 2000;13:246-53.

14- Gotfredsen K, Holm B. Implant-supported mandibular overdentures retained with ball or bar attachments: A randomized prospective 5-year study. Int J Prosthodont 2000;13:125-30

15- Theodoros T ,Konstantinos M, Kiho K and Hiroshi H. Attachment systems for implant retained overdentures. J Implant Dentistry2006 1; 24-34.
16- Jiménez-Lopez V. Oral Rehabilitation with Implant-Supported Prostheses: Implant Supported Mandibular Overdenture. Chicago, Berlin, London, Paris: Quintessence Publishing Co.; 1999.

17- Van Kampen F, Cune M, van der Bilt A, Bosman F. Retention and post insertion maintenance of bar-clip, ball and magnet attachments in mandibular implant overdenture treatment: An in vivo comparison after 3 months of function. Clin Oral Implants Res 2003; 14:720-6.

18- Prasad, D ,Krishna D Anupama Prasad and Manan Buch Selection of attachment systems in fabricating an implant supported overdenture J Dental Implants 2014 4: 176-181

19- Alqutaibi A Kaddah A Attachments used with implant supported overdenture Int Dent \& Med J of Adv Res 2016. $2: 1-5$

20- Rodrigues AH (2000). Metal reinforcement for implantsupported mandibular overdentures. J ProsthetDent 83:511-513.

21- Ramu R, KiRan K, SuDheeR Ch Remedy for Repeated Implant Retained Denture Fracture-A Challenging Case Report J of Clin \&Dia Res. 2014 8(11): 14-15

22- Ataís B, Rafael L. X. Consani, Marcelo F. Mesquita, and Mateus B. F. dos Santos Stress distribution in fixed-partial prosthesis and peri-implant bone tissue with different framework materials and vertical misfit levels: a threedimensional finite element analysis J Oral Sci 2013 55, 239-244

23- Abreu RT, Spazzin AO, Noritomi PY, Consani RLX, Mesquita MF: Influence of material of overdenture-retaining bar with vertical misfit on three-dimensional stress distribution. J Prosthodont 2010 19, 425-431.

24- Meriç G, Erkmen E, Kurt A, Tunç Y, Eser A Influence of prosthesis type and material on the stress distribution in bone around implants: a 3-dimensional finite element analysis. J Dent Sci 2011 6, 25-32

25- AkçA K., Çereli, M.C. \& Iplikçioglu, H. A comparison of three-dimensional finite element stress analysis with in vitro strain gauge measurements in dental implants. InterJ of Prostho 2002; 15-2:115-121.

26- Benzing U.R., Call H. \&Weber, H. Biomechanical aspects of two different implant-prosthetic concepts for edentulous maxillae. Int J of Oral \&Maxillo Imp 1995; 10:188-198. 
27- Lekholm U., Van Steenberghe D., Herrmann I., Bolender C., Folmer T., Gunne J., et al. Osseointegrated implants in the treatment of partially edentulous jaws: a prospective 5 year multicenter study. Int J Oral Maxillo Implants 1994; 9:627-35.

28- Slaets, E., Naert I., Carmeliet G., et al. Early cortical bone healing around loaded titanium implants: a histological study in the rabbit. Clin Oral Implants Res. 2009; 20(2): p. 126-34.
29- Ingrid Ís Nogueira S, Silvana M Miranda S, Fabiana Ribeiro da Silva, Elson Braga M Comparative study of splinted and unsplinted implant-retainedmaxillary overdentures without palatal coverage: A literature review .Braz Dent Sci 2017 Oct/Dec;20(4) 32-41

30- Ahmed, K. Splinted versus unsplinted overdenture attachment systems - no difference in clinical outcomes. Evid Based Dent 201920, 28-29 